\title{
Professor Janet Wasko: An Interview with the President of the IAMCR and one of the Key Representatives of the Politi- cal Economy of Communication Approach
}

\author{
Jernej A. Prodnik* and Janet Wasko** \\ * Social Communication Research Center, Faculty of Social Sciences, Ljubljana, Slovenia, \\ jernej.amon-prodnik@fdv.uni-lj.si \\ ** School of Journalism and Communication, University of Oregon, Eugene, Oregon, USA. \\ jwasko@uoregon.edu
}

Abstract: This paper presents an interview with Janet Wasko. She is a Professor and Knight Chair in Communication Research at the University of Oregon's School of Journalism and Communication and widely considered as one of the key authors working in the tradition of the political economy of communication. Currently she is serving as the President of the International Association for Media and Communication Research (IAMCR), one of the key international associations in the field of media and communication studies. She previously held several other positions in the IAMCR and served as the head of the Political Economy-section, which she also helped to establish. Professor Wasko published several influential books on the film industry, especially on Hollywood and the Disney Corporation. We talked especially about the influences on her approach, about her position in the IAMCR, her understanding of how the cultural and media industries work, the political economy approach in media and communication studies, and issues related to the film industry, which she mostly tackles in her own research.

Keywords: Political Economy of Communication, International Association of Media and Communication Research, Hollywood, The Disney Corporation, cultural industries, film industry
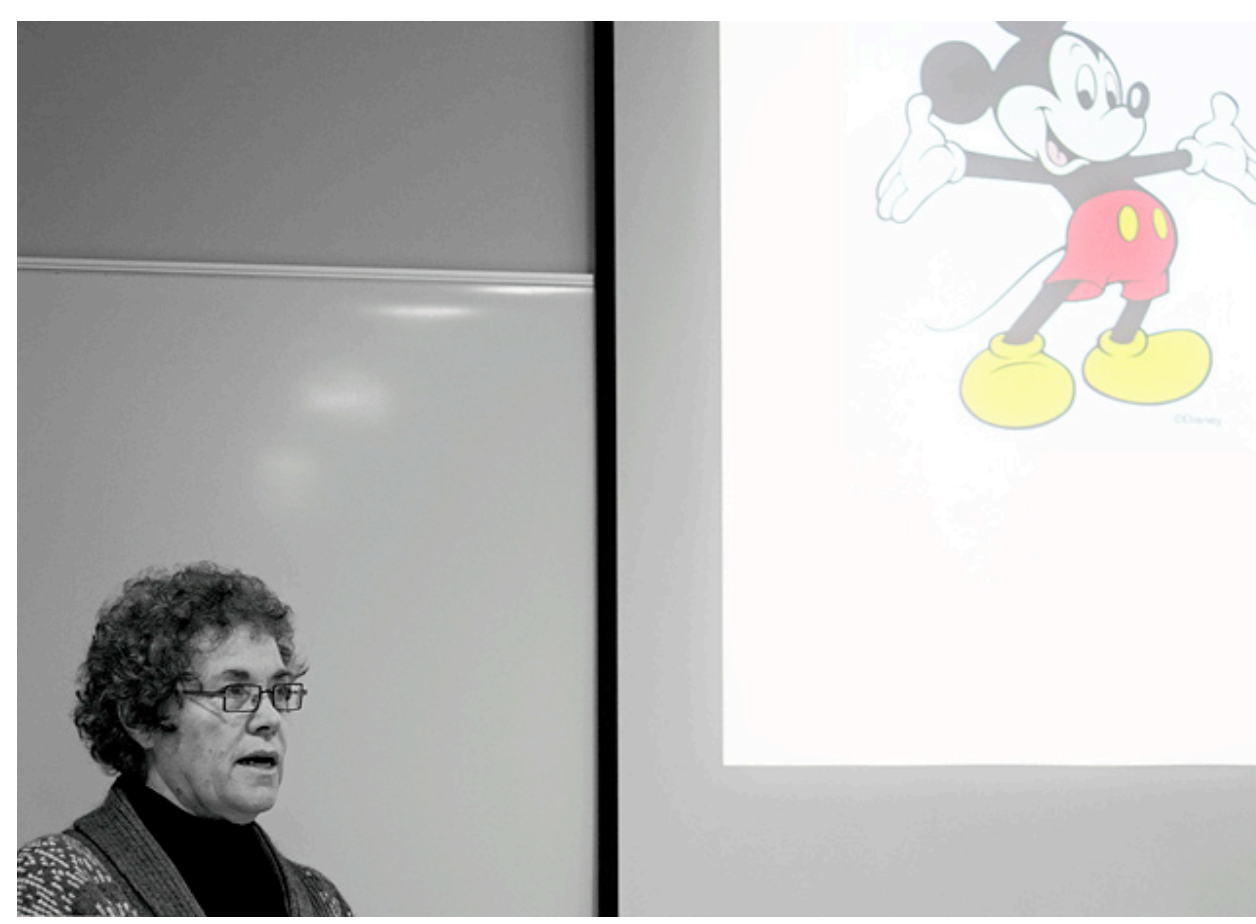

Professor Janet Wasko giving a lecture on Disney in Ljubljana, December 2013 (photo: Jernej A. Prodnik) 
Janet Wasko is a Professor and Knight Chair in Communication Research at the University of Oregon's School of Journalism and Communication. She is widely considered as one of the key authors working in the tradition of political economy of communication. Currently she is serving as the President of the International Association for Media and Communication Research (IAMCR), one of the key international associations in the field of media and communication studies. She previously held several other positions in IAMCR and also served as the head of the political economy section, which she helped to establish.

Professor Wasko published several influential books on the film industry, especially on Hollywood and the Disney Corporation, namely How Hollywood Works (Sage, 2003), Understanding Disney: The Manufacture of Fantasy (Polity, 2001), Hollywood in the Information Age: Beyond the Silver Screen (Polity, 1994), and Movies and Money: Financing the American Film Industry (Ablex, 1982). Together she authored, edited or co-edited 19 books, amongst them edited volumes The Handbook of Political Economy of Communications (Wiley-Blackwell, 2011) with Graham Murdock and Helena Sousa, Companion to Television (Blackwell, 2005), Dazzled by Disney? The Global Disney Audience Project (Leicester University Press, 2001) with Mark Phillips and Eileen Meehan, Consuming Audiences? Production and Reception in Media Research (Hampton, 2000) with Ingunn Hagen, Communication and Democracy (Ablex, 1993) with Slavko Splichal, and others.

The interview took place in December 2013 in Ljubljana, Slovenia, where Professor Wasko gave a lecture entitled Dissecting Disney: The Critique of Media Corporations at the Faculty of Social Sciences (University of Ljubljana). It was conducted around the time when the U.S. Bureau of Economic Analysis and National Endowment for the Arts released its Preliminary Report on Impact of Arts and Culture on U.S. Economy, which was the first federal attempt of an analysis of the financial extent of the narrowly defined creative industry (arts and culture) in the U.S. national economy. According to the estimates it accounted for 3.2 percent of GDP ( $\$ 504$ Billion), led by the film industry, which thus represents a considerable chunk of the American economy ${ }^{1}$. We talked especially about influences on her thinking and work, her position in the IAMCR, her understanding of how the cultural and media industries work, the political economy approach in media and communication studies, and issues connected to the film industry, which she mostly focuses on in her own research.

Jernej A. Prodnik (JAP): Professor Wasko, you are today a world-renowned scholar. You base your research in the tradition of the political economy of communication. What would you say influenced you the most and what were the reasons you decided that political economy is in fact the way to go in research?

Janet Wasko (JW): I do not think it was something that happened instantly, overnight. It was rather gradual. When I started studying media and communication I did not know there was something called political economy. But the more that I studied, the more I realised there were a lot of problems with the media. I increasingly became more critical and then found myself at the University of Illinois, where I studied with Thomas Guback; and he was very instrumental in introducing a political economic approach to studying media.

JAP: He also studied film industries like you do. Would you say he was the main intellectual influence on your work?

JW: Yes, a major influence...

JAP: And what would you say were other influences? Was it other people or maybe some books that you read at the time?

JP: Let me see...other influences at the time were the British scholars who were looking at media from a political economic perspective, including [Graham] Murdock, [Peter] Golding,

\footnotetext{
${ }^{1}$ See National Endowment for the Arts (2013).
} 
and [Nicholas] Garnham. Their work was very influential. Of course the classic theorists could not be ignored, but those who were applying Marxist theory and critical theory to media. At the time it was also Tom Guback, Herb Schiller, Dallas Smythe...

JAP: So it was especially the North American and the British tradition of the political economy of media?

JW: Yes.

JAP: The University of Illinois, which you already mentioned and where you enrolled for a PhD, has traditionally been a place for critical communication scholars. Was this so also at the time when you were studying there or was it more-so in some other time-periods?

JW: It has been a very well-known and established programme for the study of communication. Not always necessarily critical. There has been a mix of people there. In fact when I was there, cultural studies was extremely strong. In fact not cultural studies exactly, but a version of cultural studies, which they called "culturalism" at the time, following people like James Carey and others at Illinois. In fact they were quite dominant when I was there, at least at first. But increasingly more people came to study with Tom Guback and more students started studying and using political economy at that point.

That tradition was also there previously in the eighties. Because, of course, Herb Schiller was at Illinois for a while, Dallas Smythe offered the first class in the United States on political economy of communication, and then Tom Guback studied with him. There was some strong tradition, but it was mostly these individuals, critically oriented scholars, working mostly individually.

\section{JAP: So they were more or less dispersed around North America?}

JW: Exactly, yes.

JAP: Was it also your personal experiences that influenced your research? Several scholars like [Herbert] Schiller and [Dallas] Smythe you mentioned often cited the social context in which they lived. Was it also this development that influenced your approach and the fact that you were critical? Have you also felt some sort of social responsibility or responsibility for being a public intellectual?

JW: I would like to be a better public intellectual, by the way [laughs], but it is a challenge to do that. First of all, there was the influence of the sixties and the seventies, the anti-war protests, civil rights, and the feminist movement - all of those social movements. That was the context, in which I was influenced by critical and radical thinking.

But then I also worked in the media. I worked for a number of different companies in Los Angeles, in Hollywood. I worked for ABC, I worked at a television station, for Disney, and at a commercial production company, and I think in its own way that had an influence on me. Because it seemed like so much talent and resources was being wasted. There is so much more you can do with media than sell soap [laughs] and things like that. So that actually prompted me to go back to the university and finish my degrees. I think it was a combination of those things.

JAP: Not so long ago you became the president of IAMCR, which is one of the key media and communication associations in the world. So how is life at the head of such an important organization?

JW: It is busy [laughs]. It is extremely busy, with a lot of e-mails. 


\section{JAP: But it is probably also something that you wanted?}

JW: I first went to an IAMCR conference when I was studying for my Ph.D. exams. I was influenced again by Tom Guback, who suggested that it was a good organisation, so the first conference I went to was at the University of Leicester ${ }^{2}$. And at that point I identified it as the organisation that I wanted to participate in.

\section{JAP: Was it because political economy was always relatively influential within IAMCR?}

JW: No, it wasn't formally recognized at the time. There was no political economy section. However, there certainly were a lot of people who worked in the tradition and who also talked about Marxist theory, political economy, [Jürgen] Habermas, and other theorists who were not being discussed as much in United States. And so the interaction with international scholars was incredibly valuable and very important to me. I knew I could learn a lot by going there, so I just continued to go.

Shortly thereafter, there was a group that came together to form the political economy section and I participated in that. It struggled for a few years to actually establish itself in the organisation. It was not immediately welcomed or accepted by some people because IAMCR is not totally critically oriented, as some have assumed.

\section{JAP: But it is still a lot more critical than ICA [International Communication Associa- tion] for example.}

JW: Yes, and I think you can find more critically oriented people and approaches in it.

\section{JAP: So who were the people who established the political economy of communica- tion section in the IAMCR?}

JW: I actually wrote a short history of the section for the new journal The Political Economy of Communication ${ }^{3}$. It started with a group that got together the year after Leicester in Paris, calling itself the materialist group. It included Robin Cheesman from Denmark, Graham Murdock, and Armand Mattelart and a number of other people. But then it was introduced as a section that would be called the Political Economy-section and Robin Cheesman became the first head of the section.

JAP: So to go back to the original question, what were the reasons you decided that you would like to be the president of IAMCR?

JW: It was definitely not really something I dreamed about [laughs]. At a certain point it seemed to me there was a need at the time for someone who had a history with the organisation. I thought that I could contribute to the association by running for the presidency. I hope that I still am able to make a contribution to strengthen the organisation, because it really does need to be strengthened. There is a lot of competition from other organisations. But it really still is, I would say, the largest truly international organisation in the field, even if there are other ones that are growing. So I felt as though I could contribute in that way. I had been the head of the political economy section for several years, and I never really did want to be the president, but it seemed like the time was appropriate and I felt it was what I could contribute.

JAP: Do you see the support that you received from the members of IAMCR as somehow connected also to the political economy of communication as a research tradition or more because of your history in IAMCR?

\footnotetext{
2 The IAMCR conference at the University of Leicester (UK) was in 1976.

${ }^{3}$ See Wasko $(2013,4-8)$.
} 
JW: That is a really interesting question. There is no doubt that political economy has grown in the organisation and that reflects the general growth of it internationally. We did a lot of work to build the section and I participated in that. But I think it was not only my work in the political economy section; I think it was also because I participated in the organisation for quite a few years, doing a lot of other things. At one point, I helped with the newsletter, and I was in charge of the elections for several years. So people got to know my name. I got to know people beyond just the political economy section. So I think it is a combination.

JAP: Let us discuss the political economy of communication approach, because you mentioned there has been a growth of this tradition. I guess it is probably difficult to imagine that it would again have such an influence in the near future as it did in the 1970 s and at the start of the 1980s, when it also had some influence on the existing geopolitical debates. For example through the New World Information and Communication Order (NWICO) initiative.

JW: I agree, I think that the NWICO period and the attention being given to it, was a moment which really did represent a real expansion of critical thinking and critical approaches generally, not only political economy. The field itself has grown so much now; it is so big these days. There is actually room for a lot of different political economies and different approaches. I think there is the potential for influence on geopolitical debates from people doing that kind of research, but I am not sure it is an international influence. Maybe more nationally or even locally.

JAP: So this is the praxis part that you and others often make about political economy when you are saying it must also have practical influence on politics; and also address moral questions?

JW: Yes, actually trying to influence and bring about changes. But I do not know if it is at the international level as much as maybe at the national level or even local. For instance, the kind of thing that Bob McChesney is doing in the United States, with the Free Press movement and its visibility. I mean, one may not agree with some of his arguments, but that is not the point here; he is really calling attention to a critical view on the media and to their critique, calling attention to those issues. I suppose he is influential internationally, but I do not think that is where his strength is; it is a national debate that he and others have been building.

JAP: What were in your opinion the main reasons that the political economy approach had such difficulties at the end of the 1980s and in the 1990s. Was it only the social and political context, or were there other reasons?

JW: I do not know what other reasons there could be, it was political, yeah.

\section{JAP: So basically it was connected to the rise of the neoliberal order?}

JW: Yes, well, in the United States it is not only the rise of neoliberalism. It has been problematic since the 1930s and 1940s in the 20th century; the whole period in the United States of blacklisting educators, anti-communism and all of that. It is not necessarily new.

JAP: What do you feel the situation is today in the United States for critical scholarship. Is it still as difficult as it was in the past?

JW: I think I would have to say it is not. There are a lot of possibilities. That is not to say that critical researchers and educators do not sometimes have a difficult time. There is red-baiting and other things that go on and sometimes people have problems getting jobs and keeping jobs and so forth. But I think there are a lot more people with this approach. It is not the same as it was in the past when they were isolated, for example, Dallas Smythe over here, Herb 
Schiller over there. There are more people with critical approaches, but it still presents a lot of interesting situations. It still is not totally accepted and it certainly is not in the mainstream.

JAP: And what about the local environment, how do they perceive you as a critical scholar who is also influenced by Marx and Marxism?

JW: As long as I keep publishing a lot or more than anyone else [laughs] - and as long as I continue to contribute to the school that I am in, it is more-or-less okay.

JAP: I did not have only your university in mind, but also the wider environment. Sometimes it is even the politicians directly pressing on academia and academics.

JW: They do, but well, there is a general sense that there is a lot of critical thinking going on at universities. Not always, because it certainly does not dominate, but there are certain pressures that are increasing. That's because the whole educational system is being influenced by neoliberalism; the emphasis on training students for jobs, supporting the economy and so forth. That is very real, but it influences everyone in the academic setting. Some people do not mind it though, but if you are critically oriented it is especially discouraging. If it really came down to severe cuts, I think you would find those who would go first would be critically oriented. I did have a situation in the nineties when I was a part of a small, critical department within the University of Oregon and we were taken over by a larger department partially because we were known as being more critically oriented. It does happen every once in a while.

JAP: In one of the articles you recently wrote together with your colleague Eileen Meehan you pointed out that in North America, similarly to West Germany in the seventies, political economy of communication has traditionally been connected to Marxism $^{4}$. So to say, it is basically a critique of political economy. Would you say you are a Marxist or just someone who was influenced by Marx's work, but follows a more or less autonomous path that you have paved together with some other critical media and communication scholars such as Vincent Mosco or Eileen Meehan?

JW: I suppose the term neo-Marxist would apply. I think we draw a great deal of our inspiration and conceptual and theoretical framework from Marx, but of course there are different versions of Marxist theory, so I would say it is a kind of neo-Marxist approach. I find that I am fairly consistent with the approaches of the people you mentioned (Mosco, Meehan and so forth), but I also have been influenced by British political economists a great deal.

JAP: And how do the students perceive this tradition and research approach, do they find it valuable for analysing and understanding society?

JW: Well, that is the strength of the approach, because it often does help you understand the way things are developing. It is interesting that undergraduate students in the US (and I think you have to separate them), the younger students, increasingly are not so interested in theory or critical thinking. But if you start pointing out things about the media and the problems, they often will agree. However, they don't think there is any choice, you know, that there is any way to change things. So sometimes they will agree, but they are more interested these days in preparing for a job; they are very practically oriented. Only a few of them are critical. At the graduate level and with doctoral students, especially, there seems to be a lot of interest in political economy. The classes that I teach at Oregon on political economy are some of the largest in our graduate programme, so there is a lot of interest. What I think that indicates is that they see this approach as a valuable tradition; they see it as approach that is more or less accepted and they need to know about it. Some of them agree with the approach, some

\footnotetext{
${ }^{4}$ See Meehan and Wasko $(2013,40)$; cf. Hoffmann $(1983,12)$ for West Germany in the 1970 s.
} 
do not; some take the course just to find out more, and some use the approach together with other approaches. But I have had over the years a steady number of students who have adopted the political economy approach.

JAP: It seems a little bit contradictory, because if you understand political economy you can actually be a more successful "capitalist". It is funny, because if you read Marx you can draw some very practical instructions.

JW: Absolutely, it is possible that some of our work actually does help some of the media companies [laughs].

JAP: It can in fact help students to get a job and to understand how corporations actually must work.

JW: And even the media corporations themselves, if they pay attention to what we do. I can give you some examples. One is from my dissertation, which I did on financial institutions and the film industry and I interviewed a number of bankers. After I published the results, a banker contacted me (he was someone I did not interview), but he thanked me for my book, because he learned so much about the way the film industry worked. He must have skipped over the part about Marx; I don't know what he did with that [laughs], but it is a concrete example of how we can actually assist them.

JAP: This is why Zygmunt Bauman never does anything really practical, he is more abstract, so no one can take advantage of his intellectual work and exploit it.

JW: Maybe that is the answer, but I do not think we can stay at a purely theoretical level all the time [laughs]. We have to look at things empirically. Another example was the Disney Company, who was at one point interested in the results of the Global Disney Audiences Project $t^{5}$ that we did and invited me to help improve their brand at some retreat or something [laughs].

\section{JAP: So you did not decide to go to the Disney World to help them?}

JW: No, I didn't go anywhere to help them [laughs]. But most often I think they ignore critical work. There are plenty of academics, who do help them, that's for sure, and they sometimes actually work for them. I think when it comes to critique, only if maybe you are criticising a specific movie in public sources or media outlets, but otherwise I don't think they read what we write.

JAP: Do they have a lot of choice when deciding how to operate? You often point out these underlying basic preconditions, under which they have to run. For example, they have to try and be as profitable as possible. How much choice do they have here? Marx pointed out that a capitalist is basically capital embodied, so (s)he does not have a lot of choice in his/her actions, (s)he has to compete on the market, and shareholders nowadays are for example very strict, if you are not successful they will fire the managers, directors...

JW: Yes, or they move their investments to another company. All of those things I think are the case and it is not so flexible. But I think that they do have some choices in terms of building capital and profits; there are a lot of different options. The big problem is to figure out what will be profitable and I don't think it is always absolutely clear, especially in the media and entertainment areas.

\footnotetext{
${ }^{5}$ See Wasko, Philips and Meehan (2001).
} 
JAP: This is probably why they were interested in your research on audiences.

JW: Yes, right, what kinds of insights they can find.

JAP: ...which incidentally also brings us to the question of how political economy and cultural studies clashed in the 1990s. Together with some other political economists, like Graham Murdock, you advocated, so to say, an integrative approach that would try to bring together both intellectual strands. But you still based your research firmly in political economy. Do you see it as some basis that simply cannot be overlooked when one is doing critical communication scholarship?

JW: I would say that political economy must be privileged, because it is the foundation. But that is not necessarily a rejection of cultural analysis, including reception by audiences and fans. We cannot neglect or ignore them. And I think a lot of people who embrace political economy in terms of their approach and their work, do not ignore cultural aspects and audiences. There are increasingly more people who do that kind of integrated work. It is hard to do it all; that is one thing; it is a challenge to do a complete analysis of something like Disney or another phenomenon. Not only because of the time involved, but also because of expertise. I fully admit that I am not an expert textual analyst or discourse analyst, but I can work with others and I think that is one of the things that has been the case for quite awhile; people are working together.

\section{JAP: ...Which can bring a more holistic insight in the analysis?}

JW: Yes. Actually, some individuals are fairly good at doing the whole thing. I think actually Eileen Meehan is quite good with in integrated approach, and so is Graham Murdock and a lot of others. But I prefer to work with other people who have that kind of expertise.

JAP: What are in your opinion the main differences between these two approaches? Is it this focus on production and distribution when it comes to political economy on the one hand, and consumption, when it comes to cultural studies on the other, which could be seen as two different aspects of social reality, so to say?

JW: Yes, that would be one way you could describe the two approaches. Although I would certainly think that political economy is paying a good deal of attention to consumption.

JAP: But probably in a different way, not in a sense of how audiences perceive messages, political economy does not ascribe so much focus to the meaning of the messages?

JW: Exactly, not as much on the meaning and ideology; but of course one of the reasons that we are interested in understanding what is produced and why it is produced is because of the ideological content of the messages.

JAP: It is also this basic level of political economy that often influences what ideology there will be in the messages; it encapsulates basically what possibilities there are.

JW: It sets the stage for things, you know. There could be a lot of things going on, on the stage, but it sets the framework and the parameters. And as you pointed out yesterday [in the conversation we had], there are contradictions where it would seem that a corporation would not want to produce something that is anti-corporate.

JAP: ...At least in its meaning, but it still brings in profits for them. 
JW: Yes, there are publishing companies that make money on producing a lot of books by Marx, for instance.

JAP: In a debate we recently had with Professor Slavko Splichal, he said that in recent times there has been a very problematic - so to say - emptying out of the meaning of concepts that were in the past mainly used as critical landmarks for social research. The Cultural Industries School that is also based on the approach of political economy does for example not reflect on the concept of cultural industries, it just takes it as a given. Do you think a historical perspective is of importance? You probably still feel that concepts like the public sphere or cultural industry have to be reflected upon, even though they are used in the popular discourse today as something completely unproblematic.

JW: I would say his analysis is correct and insightful. We were talking about this yesterday and I think it is represented in a lot of different ways. First of all, even though some of our students do research, study and make use of political economy, sometimes they do not really look at the historical evolution of these concepts and actually use them in a very superficial way. But also there are new approaches that neglect these historical concepts, or even purposely reject them. Eileen [Meehan] and I recently critiqued this trend towards media industries studies, which continues to grow ${ }^{6}$. There are other very good critiques of creative industries, production culture, production studies, convergence in media, and so on.

JAP: So these are basically affirmative concepts that are not questioning anything, they just take something that can be used by capital or in market research.

JW: Yes, some people using these approaches claim to be critically oriented, but I think ultimately they are not. Often it is pretty blatant; it is a very celebratory kind of stance they have toward the industries they are studying. They are not critiquing them and they are often blatantly working with them. For instance, in cinema studies, for years and years - at least in the United States, but I think elsewhere as well - it was rare to find any kind of political economy or interest even in the industry itself, in the economics and the business by film/media scholars. The interest was mainly in the text and then in audiences. Now there is more and more attention to the industry, the business, even labour to some extent. However, it is often not from a critical position and some of these authors reject political economy for reasons that are false or very political.

JAP: What would you say is critical in the perspective of the political economy of communication? What are the main tenets of being critical and of having a critical approach?

JW: Looking at who is benefiting. Looking at the issues of ownership and control, looking at the distribution of wealth... There is a good deal of ignorance about the distribution of wealth in terms of media companies and the enormous amounts of money that people make from media activities, so it is actually taking a position about that. Noncritical approaches are accepting, for instance, the role of advertising to support the media without any kind of critical sense. It is assumed to be the best way to support the media of course, without much interrogation of the consequences of that.

JAP: You probably don't ascribe to being neutral in social research. Is that even possible?

JW: No, no, of course not.

\footnotetext{
${ }^{6}$ See Meehan and Wasko (2013).
} 


\section{JAP: Are you sure?}

JW: [laughs] Well, that does not mean we do not try to do empirical work and look at what is actually going on. For instance, you can argue that concentration is certainly the case in a lot of media industries, but there are also points where there is more competition. You have to observe that; you cannot merely assume that it is all concentrated. We may take a moral position and argue that a system is not the best of possible systems, but you also have to look at it empirically and see what is actually happening. I think it is one of the arguments that Nicholas Garnham makes in his piece in The Handbook of Political Economy of Communications, that there needs to be a more careful analysis of changes and not relying on old arguments $^{7}$. Dwayne Winseck also makes this case ${ }^{8}$. Still, I think there is a lot of empirical work that is done.

JAP: But still, there are probably always some presuppositions that you take when you go and research something?

JW: Yes, but you can also be wrong. I think you can take a position, but you also have to support your position.

JAP: We talked earlier about this day-to-day operation of the film industry and other media industries and how they are restricted in their operation. This probably extends to every corporation in media and communication, no matter how they understand or present their own role; they cannot act in a much different way than they do, as they must produce different commodities. This includes social media such as Facebook or Google, so their ultimate and underlying goal probably cannot be social responsibility, even if this is what they really wanted. Google representatives for example said they will never censor their search engine in China and a little later they did, as China is too big of a market for them.

JW: As I was saying in my lecture [yesterday], you have to be careful with some generalisations. For instance, I didn't know as much about Bertelsmann until recently ${ }^{9}$, but they do seem to have some policies of workers' control. It also seems to be a much more socially responsible company than some of the U.S.-based corporations. And even some of the U.S. corporations have to pay attention to their image, because they make so much money they try to also be perceived as socially responsible.

JAP: Do you think this is also down to how they are owned and who owns them? For example, financial markets and some "anonymous" owners probably do not care what people think about them.

JW: And some of them may actually have some strong, sincere feelings about these issues. This is again where you have to look at an instrumental analysis, who is involved and different policies that people may have. For example, compare Rupert Murdoch and then Ted Turner. Some may perceive Ted Turner as kind of "crazy", but he actually has supported some projects that you can say are not typical of other capitalist media owners. There are some of the other new company owners, like Bill Gates [he founded the Bill \& Melinda Gates Foundation]. Well, they have so much money, they might as well do something to help someone [laughs]. You can look at that cynically and say it is because they want some tax write-offs or something like that, but I think you cannot always assume they are "evil". They certainly have been successful, and some are greedier than others. And this does not mean

\footnotetext{
${ }^{7}$ See Garnham (2011).

${ }^{8}$ See for example Winseck (2011).

${ }^{9}$ Professor Wasko mentioned in her lecture at the Faculty of Social Sciences (Ljubljana) a book by Scott Warren Fitzgerald, in which he analyses very different approaches by three corporations in the field of media and communication: Time Warner, Bertelsmann AG and News Corporation. See Fitzgerald (2012).
} 
you have to support the whole system, in which they were able to become so rich, because it is still inequitable and unfair to many, many people.

JAP: You have mostly worked on the film industry, especially on Hollywood and Disney, and you have recently pointed out that at least for the time being Hollywood still remains unchallenged globally. In the past it has been able to adapt to the changes, which is also why this historical perspective is so important. It went through big changes, not for the first time, but it has been able to adapt at least to a certain point by now.

JW: Yes, I think it's crucial to do historical analysis to see if this is something that is really new. We have to examine how companies, Hollywood, in this case, have been able to survive, to adjust strategies and so forth. And the film industry has been very good at that.

JAP: Because there have been some obvious changes, but there has also been continuity in this. So this is the contradiction that is often overlooked.

JW: Especially if you look at the film industry, it is mostly the same companies that dominated in the 1920s that dominate today.

JAP: And if we look at Disney it has been able to diversify its operations so it was at least to an extent able to adapt to the changing market environment all the time. But there are often also contradictions within these corporations.

JW: Yes, absolutely. Disney is an exception in a way to the other very large companies in the film industry, because they were a very small company up until the 1950 s, when they did not even distribute their own films. They did not have that integrated system. They produced the films and the merchandise. From the 1950 s they started really diversifying with theme parks and television. Then in the 1980 s they started acting like a big major corporation, a conglomerate, and getting involved in a lot of other areas, like cable and expanding into television. So some people would say they became "more corporate" and they went against what Walt Disney did, but it was a matter of becoming more diversified and much more like a conglomerate.

JAP: So this was mostly happening in the 1980 s?

JW: Yes.

JAP: ...Because this is also a time of the rise of financial capitalism. So these conglomerates started to connect, looking for synergies and so on?

JW: Those are two different things. The synergy had already been there with Disney and just kept growing, in the way they connected their films and the characters from the films with merchandise, and then into theme parks and into television. So their synergy strategy was actually strengthened in the 1950s.

Financial capitalism and financialisation is an interesting concept, because I don't think it is new.

JAP: If you look into 19th century it was already there...

JW: Yeah.

JAP:But it has also grown so much at the end of the 1970 s and especially in the 1980s. 
JW: True, but it also was the case in the 1930s. For instance, if you look at the relationship between financial institutions and the film industry, which I did historically, there were banks that owned film companies in the end of the 1930s. The Chase Bank owned twentieth Century-Fox. And that kind of a very close relationship was quite common in the 1930s and then into the 1940s. Actually, finance capital was seen to be very intense in the 1930s.

JAP: In one of the articles you even wrote it has been of key importance for the development of Hollywood.

JW: Yes, so there may be more emphasis on profit and relationships with banks, but seriously, I do not think it is necessarily new. It would be an interesting discussion though, because a lot of Marxist political economists have written about that, like at my university John Bellamy Foster. I have not had this discussion with him. And I am not so sure about the entire economy, but certainly with the U.S. film industry and the media, there have been banks involved throughout its history, but in various ways. So that whole idea of financialisation and finance capitalism is not completely new.

JAP: Especially not for the media industry, where many companies became corporations already at the start of the 20th century.

JW: Absolutely and we can expand that to telecommunications, like AT\&T and so forth.

JAP: As we were talking about Hollywood earlier, do you think that the cultural imperialism thesis is still valid today? Are we living in a post-imperialist era or "not yet", as Herbert Schiller put it at the start of the 1990s? ${ }^{10}$ He pointed out that in the global era it is not necessarily American corporations anymore, like they were before, but corporations as such that have an influence.

JW: Of course, there have been marketisation and privatisation trends. But I think the cultural imperialist argument has been revised a bit. Perhaps there never was that kind of extremely strong influence in effect of, for instance, American media products on different cultures.

JAP: Do you think that the cultural imperialism thesis is more applicable to the fact that basically everything became incorporated into the capitalist system or more on the side of the effects? Personally I think the thesis was much more valuable when it came to analysing that everything was changing in that one way in its operation, if I am not mistaken this was also called "Americanisation" at some point.

JW: Right, but there were arguments that Schiller and others made about the ideological influence and effect. Some actually critiqued him for that and I think it was one of the reasons why the cultural imperialism argument could be rejected. There is the notion that has been introduced of soft power or soft influence, which I think is far more often the case than hard cultural domination or ideological domination. There were not that many studies actually done to back that up and now increasingly there are, but also I think the shift to arguing that it is the market system that is being promoted and accepted.

JAP: It is also very difficult to explain whether this influence would be intentional or how it is transmitted. It has always been a problematic and complex subject. But even in this globally integrated capitalist system, you point out that nation states still have huge importance; for example in setting the legal framework and the legislation, one such example being intellectual property rights. Nation states are not really completely gone, are they?

\footnotetext{
10 See Schiller (1991/2006).
} 
JW: They are not. Of course, it varies across countries, but the state is still very important.

JAP: Also in the United States throughout the last fifty years, there have been such huge public investments in information and communication technologies, which can hardly be overlooked.

JW: Absolutely, and there are still attempts at regulation. But regulation is flawed in many ways.

JAP: ....and biased towards corporations.

JW: It is also supported in various ways. I know I keep using examples of the film industry, but they are not regulated per se, except as corporations, however they look to the support of the state, including getting into international markets, protection of intellectual property rights, especially in fighting piracy, and a lot of other things, even subsidisation of film production. For instance, now within the United States, every state has some kind of office or commission that provides various kinds of subsidies for film companies to shoot films in their state. And it is very competitive; they have successfully drawn some of the production work away from Los Angeles. That is in a way drawing on support from the state. In very interesting ways in some places it is detrimental to the area, even though the argument is that it brings in money, investment, and is good for the economy. But every state in the U.S. has one of those; some of course are more successful than others.

JAP: If we end our conversation on a different, perhaps more positive note. There have been huge protests in the last years against the neoliberal order and for a more just world. Are we able to build a more just world?

JW: Well, that is an easy question [laughs]. One can hope. I think one of the things that has been emphasised by the Occupy movement has been the inequity in distribution of wealth. It is much more visible in terms of the public discussion, at least people have heard of this "one percent" now. But then again, I do not want to use the United States as an example, because it could be hopeless as a leader in terms of changing the world. The situation in the United States is almost deadlocked in terms of functioning politically, because of the rise of the far right. And there is no far left, and not even much of a left movement. I am sorry, there are just a couple of guys, you know what I mean? [laughs] There are the people from the Occupy movement, but they are not in Washington, they do not have any positions of power. So there is no balance. I don't think you can look at the United States very often for some hope because the system is so entrenched. However, I should remain hopeful - there are surprises every once in a while. And after all, maybe we need to remember Gramsci's pessimism of the intelligence, optimism of the will ${ }^{11}$.

\footnotetext{
${ }^{11}$ See Gramsci $(1971,175)$.
} 


\section{References}

Fitzgerald, Scott W. 2012. Corporations and Cultural Industries: Time Warner, Bertelsmann, and News Corporation. Lanham, MD: Lexington Books.

Garnham, Nicholas. 2011. The Political Economy of Communication Revisited. In The Handbook of Political Economy of Communications, eds. Janet Wasko, Graham Murdock and Helena Sousa, 41-61. Malden, Oxford: Wiley-Blackwell.

Gramsci, Antonio. 1971. Selections from the Prison Notebooks. London: Lawrence and Wishart.

Hoffmann, Burkhard. 1983. On the Development of a Materialist Theory of Mass Communications in West Germany. Media, Culture and Society 5 (1): 7-24.

Meehan, Eileen R. in Janet Wasko. 2013. In Defense of a Political Economy of the Media. Javnost The Public 1 (20): 39-54.

National Endowment for the Arts. 2013. U.S. Bureau of Economic Analysis and National Endowment for the Arts Release Preliminary Report on Impact of Arts and Culture on U.S. Economy. Accessed December 29, 2013. http://arts.gov/news/2013/us-bureau-economic-analysis-and-nationalendowment-arts-release-preliminary-report-impact\#sthash.VIvoAUVC

Schiller, Herbert Irwing. 1991/2006. Not Yet the Post-Imperialist Era. In Media and Cultural Studies: KeyWorks (Revised Edition), eds. Meenakshi Gigi Durham and Douglas Kellner, 295-310. Malden, Oxford: Blackwell Publishing.

Wasko, Janet. 2013. The IAMCR Political Economy Section: A Retrospective. The Political Economy of Communication 1 (1): 4-8. Accessed December 30, 2013. http://polecom.org/index.php/polecom/article/view/11/148

Wasko, Janet, Mark Philips and Eileen Meehan, eds. 2001. Dazzled by Disney? The Global Disney Audience Project. Leicester: Leicester University Press.

Winseck, Dwayne R. 2011. The Political Economies of Media and the Transformation of the Global Media Industries. In The Political Economies of Media: The Transformations of the Global Media Industries, eds. Dwayne R. Winseck and Dal Yong Jin, 3-48. London, New York: Bloomsbury Academic

\footnotetext{
About the Authors

Jernej Amon Prodnik

is a researcher at the Social Communication Research Centre, Faculty of Social Sciences, University of Ljubljana (Slovenia). He defended his PhD in media and communication studies at the University of Ljubljana in 2013 under the title Political Economy of Communication and Structural Transformations of Capitalism. His principal research interests include critique of political economy (with a focus on media and communication), structural transformations of capitalist societies, and the wider social context of technological changes and democratic potentials brought about by new technologies.

Janet Wasko

is Professor \& Knight Chair in Communication Research at the University of Oregon. Her research and teaching areas include the political economy of communications, media theories and international communication issues. She is author, co-author or editor of 19 books including Understanding Disney: The Manufacture of Fantasy; Dazzled by Disney: The Global Disney Audience Project; and The Handbook for Political Economy of Communications. She is currently serving as the President of the International Association for Media and Communication Research (IAMCR), see:

http://www.iamcr.org/.
} 